\title{
Emotional States, Coping and Irrational Beliefs in a Group of Cancer Patients
}

\section{Clara Pérez Cárdenas ${ }^{1 *}$ and Lien L Camargo Legorburo²}

${ }^{1}$ Profesor e Investigador Auxiliar, Policlínico Docente "Dr. Mario Escalona Reguera", Habana, Cuba

${ }^{2}$ Psicóloga de Grupo Básico de Trabajo, Policlínico Docente "Dr. Mario Escalona Reguera", Habana, Cuba

*Corresponding Author: Clara Pérez Cárdenas, Profesor e Investigador Auxiliar, Policlínico Docente “Dr. Mario Escalona Reguera”, Habana, Cuba.
Received: March 19, 2020

Published: March 30, 2020

(C) All rights are reserved by Clara Pérez

Cárdenas and Lien L Camargo Legorburo.

\section{Abstract}

Cancer is one of the chronic diseases with the highest incidence today. According to the World Health Organization, worldwide, cancer mortality is expected to increase by $45 \%$ between 2007 and 2030; and that it will go from 7.9 million to 11.5 million deaths, due in part to demographic growth and an aging population.

According to data offered in the Statistical Yearbook of Health (2013) in Cuba, cancer is the first cause of death for the population, occupying the first place among the ten diseases that cause mortality. The treatments turn out to be extremely aggressive and in many cases produce collateral consequences that affect the quality of life of the patients.

Taking into account the role of psychological factors in the adaptation to the disease, throughout the process and in the quality of life of cancer patients, it is possible to understand and value the need and importance of the work of the psychologist in the care of these patients.

In this sense, the article that is based on research results made in a health area, that is, at the primary level of care, will allow a timely and necessary approach to emotional states, coping styles and irrational beliefs that are verified in a group of cancer patients in a disease-free interval. In this way, research is considered to have a fundamental diagnostic and practical value. In order to increase the quality of life in these patients, the results of the study would favor the elaboration of individual or group psychological intervention strategies. Only by taking care of the inner world of the patient who has an oncological diagnosis, the health actions that are developed with him and with his families, will be effective. At the same time, elements on these psychological aspects are provided specifically in the disease-free periods, a topic that has been little studied in the area of Psycho-oncology.

Keywords: Cancer; Emotional States; Coping Styles; Irrational Beliefs

\section{Introduction}

Cancer is not a unique disease, under this diagnosis there are grouped no less than 200 types of diseases with different location, etiology, clinical, evolution and prognosis, but with common biological foundations: uncontrolled cell growth with loss of differentiation and ability to spread, invading nearby tissues and causing metastasis [1].

The diagnosis of any of its types, usually causes a series of negative emotional reactions and the expectation of a life in which the pain will remain present. Among the most frequent reactions, those associated with anxious and depressive symptoms stand out: dysphoria, decreased sexual desire, sleep disorders, changes in appetite, fatigue, slowness and/or psychomotor agitation, low self-esteem, guilt, difficulty concentrating, difficulty make decisions and suicidal ideation [2].

In the literature, it is expressed that the so-called disturbing emotions influence the onset of diseases and also hinder recovery. It is argued that people who experience chronic anxiety, prolonged periods of sadness and pessimism, continuous tension or hostility, relentless suspicion, are at twice the risk of contracting an illness [3]. The perception of the disease and the meaning that the individual gives it, influence their emotional responses and the coping behaviors they develop towards it.

Another of the lines of research that have been shown in relation to the existence of psychological factors and their intermediation in 
cancer, are those associated with the coping styles used by patients and the associated psychosocial and demographic variables. It has been identified that coping, social support networks and family functioning are mechanisms that intervene in the regulation and adaptation to the disease and facilitate the psychological adjustment of the patient [4].

The importance of personality and coping mechanisms are highlighted, as well as stress in the genesis and/or progression of the tumor. It is further thought that emotions related to the stress process, especially emotions related to loss events, have a specific weight in the direction of the health-disease process [1].

The unity that exists between the psychological, biological and social elements in the health-disease process in any individual is clear. However, there is still a little worked area within Psycho-oncology, it is the evaluation and psychological intervention in cancer survivors, in the so-called "disease-free intervals", that is, controlled patients, where the disease is not active, but that they continue to worry about fear of relapse, feelings of physical harm and infertility and experience emotional reactions of depression and anxiety, feeling of decreased control and vulnerability, uncertainty about the future.

\section{Methods and Designs \\ Research problem}

What emotional states, coping styles and irrational beliefs does a group of cancer patients from the Mario Escalona Teaching Polyclinic present in Alamar, 2015?

\section{General objective}

Describe the emotional states, coping styles and irrational ideas found in a group of cancer patients belonging to the Mario Escalona Teaching Polyclinic, in Alamar.

\section{Specific objective}

- Identify the emotional states (anxiety and depression) and the coping styles that appear in a group of cancer patients.

- Classify the irrational ideas present in a group of cancer patients.

\section{Type of investigation}

The present investigation was carried out by the authors without the contribution of any other author or institution. It is a mixed investigation given the relevance of the quantitative and qualitative methodology for a greater understanding and depth in the analysis of its results. Absolute and relative frequency analysis is used. The constructed meanings of each of the people around their experiences are dismantled, giving a protagonist role to subjectivity.
It is a descriptive and cross-sectional investigation, studying emotions, beliefs and coping in each period of time. Their results will reveal the expressions of these categories in the cancer patient.

\section{Materials and Methods}

Selection of the study group

The university contains 32 cancer patients belonging to the health area. The sample design is non-probabilistic for type subjects that meet the following criteria:

Inclusion criteria:

- Living in the health area where the study will be carried out.

- Must be between 30 and 69 years old (adulthood), as these ages are one of the highest incidence of the disease according to the 2014 Health Yearbook.

- Have a secondary or higher education level with a view to promoting understanding of the instructions and exchange with the examiner.

- Be in a period of disease-free interval.

- Possess physical validity for carrying out activities of daily life and for participation and social integration.

- Agree to participate in the research (Informed consent; Annex 1).

\section{Exclusion criteria}

- Be acting as the main caregiver of another individual at the time of the study to avoid biases in the results obtained, mainly in those associated with emotional states and irrational beliefs.

\section{Exit criteria}

- Not having completed the process of applying psychological tests, for any reason.

The study group consisted of 17 subjects with a mean age of 63 years, with a predominance of women $(76 \%)$, and secondary school level (41\%). The occupations that predominated were being retired and being housewives (each of them represented by $47 \%$ of the total of subjects studied). On the other hand, the studied group had a slight predominance of breast cancer and colon cancer compared to the rest of the pathologies, represented by $29 \%$ and $18 \%$ respectively (See annex \# 2).

Instruments for collecting information

- Trait-State Anxiety Inventory (IDARE) (Annex 3): Self-assessment inventory, designed to assess two relatively independent forms of anxiety. 
- Trait-State Depression Inventory (IDERE) (Annex 4): Self-assessment inventory, designed to assess two relatively independent forms of depression.

- Lazarus and Folkman coping scale (Annex 5): Self-registration and can be self or hetero-applied.

- Irrational Beliefs Questionnaire (Annex 6).

- Interview (Annex 7).

Procedures

The selected patients were presented with the research, the rights they possess before it and their consent to participate in it was requested.

At that same meeting, the application of the instruments for collecting the information began. Two work sessions were carried out with the purpose of reducing the psychological fatigue of the patients and making the moment of evaluation more accepted: considering the particularities of each subject. In the first session, techniques to measure emotional states were applied, and in the second session, they evaluated coping styles and irrational ideas. The interview was conducted at the end of the second session. In general, the conditions necessary for the proper development of the psychological evaluation process were considered.

Finally, the results obtained from absolute and relative frequencies were analyzed. In cases where it was necessary, content analysis was also used.

\section{Results}

\begin{tabular}{|c|c|c|c|c|c|c|c|c|}
\hline \multirow[b]{3}{*}{ Levels } & \multicolumn{4}{|c|}{ Anxiety } & \multicolumn{4}{|c|}{ Depression } \\
\hline & \multicolumn{2}{|c|}{ Anxiety as a State } & \multicolumn{2}{|l|}{ Anxiety as a Trait } & \multicolumn{2}{|c|}{ Depression as a State } & \multicolumn{2}{|c|}{ Depression as a trait } \\
\hline & Number of Subjects & $\%$ & Number of Subjects & $\%$ & Number of Subjects & $\%$ & Number of Subjects & $\%$ \\
\hline Alto & 3 & 18 & 5 & 29 & 6 & 35 & 1 & 6 \\
\hline Medio & 13 & 76 & 12 & 71 & 10 & 59 & 9 & 53 \\
\hline Bajo & 1 & 6 & & & 1 & 6 & 7 & 41 \\
\hline Total & 17 & 100 & 17 & 100 & 17 & 100 & 17 & 100 \\
\hline
\end{tabular}

Table 1: Distribution and frequency of subjects according to the levels of anxiety and depression found.

Source: Application of IDARE and IDERE Questionnaires.

As can be seen in the group of patients studied, anxiety and depression predominate as a medium-level state; represented by $76 \%$ and $59 \%$ of the total of subjects studied respectively. Anxiety and depression as a trait were similarly presented at a medium level but with lower scores: anxiety as a trait was found in $71 \%$ of the cases and depression as a trait was found in 53\% of them.

On the other hand, a greater number of patients with high levels of depression as a state (represented by $35 \%$ of the total of subjects) was observed, while anxiety as a trait was the one that showed the highest frequency of subjects in high levels of anxiety (being this way for $29 \%$ of the total).

Anxiety and depression were found to be present in 100\% of them with scores ranging from medium to high level. However, in the case of depression as a trait, there were $41 \%$ of subjects with low levels of depression.

The results obtained through the interview, confirm that the total of interviewed subjects $(100 \%$ of them) manage to identify the presence of anxiety; associated with manifestations that experience uneasiness, sustained worry, sleep difficulties, nervousness, chest tightness, headaches and stomach pain as the manifestations that most often experience.
An example of this are the following phrases: "one cannot be calm", "it is as if I lacked something to do but I do not know what it is," "I feel that something bad is going to happen", "I am worried about the future", "I have trouble falling asleep", "I wake up and wake up with palpitations", "I get tense, stressed", "squeezes my chest", "when you have an idea that does not get out of your head and in the end it bothers you from spinning around, "if something worries me a lot, my stomach hurts right away", "I feel a jump in my stomach... ". It has been found in studies carried out with cancer patients that they experience high levels of anxiety, and associate it with the perception of a threatening or harmful stimulus that causes an increase in the physiological activation of the autonomic nervous system in the body, resulting in physiological changes. transients such as: acceleration of the heart, rapid breathing, sweating, alertness and desire for protection [5].

In the case of depression, there were fewer subjects who recognized it (that is, in $59 \%$ of them). They associated it with the presence of sadness, lack of desire to do things, lack of appetite, pessimism, isolation, feelings of worthlessness and helplessness.

In this way it is reflected in phrases such as: "when one is sad", "wanting to cry", "there are days when I don't want to do anything 
and I don't want to have to get up", "my appetite is taken away", "sometimes I think that everything goes wrong for me", "I get negative", "those days I would not want to have anyone around, I get stuck in the bathroom and I do not leave until I finish crying", "one is useless", "a Sometimes I would like to help more at home but I can't, I get tired very quickly", "I am genius to see things to do and not be able to get to them".

It should be noted that the elements or situations most associated with the presence of anxiety according to the subjects interviewed were family problems (in $100 \%$ of them), everyday life situations (70\% of them), economic difficulties (65\%), visits to the doctor for a check-up or follow-up (53\%) and when they lack medicine (41\%).

Similar results are indeed found in the literature; the existence of fears, psychological discomfort and stress in the days prior to medical check-ups is mentioned, highlighting that these days patients may experience increased anxiety, difficulty concentrating and sleeping, which in some cases requires pharmacological treatment. At the same time, they point out that fear and anxiety are intensified by any physical symptom, since it is inevitable for the patient to associate it with the presence of the disease [6].

The situations or elements that mostly relate to the presence of depression were the oncological treatments they went through and their side effects $(100 \%$ of the total number of subjects who recognize this emotion), the impossibility of leading a more active life due to the limitations of the disease $(70 \%$ of them), having to retire after the arrival of the disease ( $60 \%$ of them), the loss of a loved one (50\% of them) and the existence of family problems (30\% of the total of subjects who acknowledge having manifestations of depression).

According to Zúñiga and Carazas [7], it is extremely difficult for cancer patients to assume the changes that occurred in their daily lives due to their disease; they had to put aside their activities at times totally, which had an impact on them not only financially but also socially, labor, family and above all emotionally.

Even though more than half of the subjects interviewed reported frequent manifestations of anxiety ( $88 \%$ of them), only $24 \%$ of the total of subjects who identify it as experienced, value the need for treatment; while $70 \%$ of those who recognize depression in $50 \%$ value the need for psychological or psychopharmacological treatment to decrease the intensity and presence of these manifestations.

In general, in this study an emotional state predominates with anxious-depressive disorders, which are not necessarily structured as a disorder, although they cause discomfort in the patient.
In these cases, this result could represent the psychological impact that the disease generates in a person's life.

The results therefore coincide with Garduño, Rivero and Sánchez when they refer that cancer usually causes a series of negative emotional reactions in the patient, highlighting as one of the most frequent reactions those associated with anxious and depressive symptoms [2]. Other authors agree that both experiences have a great impact on the quality of life of cancer patients [8]. These results also confirm the existence in the studied subjects of characteristics or features typical of the type $\mathrm{C}$ pattern, following what was stated by Sebastián, León and Hospital. These subjects tend to suffer negative emotions and have difficulty expressing them, which is why they experience depression, anxiety, low levels of neuroticism, among others, and generally tend to have greater emotional losses and negative life events [9].

Another important aspect of the research has been evaluating the coping styles that the studied subjects possess (Table 2).

\begin{tabular}{|c|c|c|}
\hline Coping strategies & Number of subjects & $\mathbf{\%}$ \\
\hline Self-control & 13 & 76 \\
\hline Planning & 11 & 65 \\
\hline Distancing & 9 & 53 \\
\hline Positive reassessment & 9 & 53 \\
\hline Search for social support & 5 & 29 \\
\hline Confrontation & 2 & 12 \\
\hline Escape-avoidance & 2 & 12 \\
\hline Acceptance of responsibility & - & - \\
\hline
\end{tabular}

Table 2: Distribution and frequency of subjects according to the coping strategies used.

Source: Results of application of the Lazarus Coping Styles Scale.

The results obtained in this sense show a predominance of strategies that focus mainly on self-control (76\% of them), planning ( $65 \%$ of cases), distancing and positive reevaluation (53\% of the subjects studied). None of the participants in this research accepted responsibility as this coping strategy.

As observed, no striking differences were identified according to the sex of the patients, although taking into account the results, it seems that in the case of men, self-control and positive reevaluation are more privileged (each represented by $100 \%$ of them); while in the group of women self-control (71\% of them) and planning (with 64\%) are prioritized.

Both sexes seem to agree that the least used strategy is flight-avoidance $7 \%$ of the total of women studied and $33 \%$ of the total of men in the group). However, the confrontation only oc- 


\begin{tabular}{|c|c|c|c|c|}
\hline \multirow{2}{*}{$\begin{array}{c}\text { Coping strategies } \\
\text { employed }\end{array}$} & \multicolumn{2}{|c|}{ Female } & \multicolumn{2}{c|}{ Male } \\
\cline { 2 - 5 } & $\begin{array}{c}\text { Number of } \\
\text { subjects }\end{array}$ & $\%$ & $\begin{array}{c}\text { Number of } \\
\text { subjects }\end{array}$ & $\%$ \\
\hline Self control & 10 & 71 & 3 & 100 \\
\hline Planning & 9 & 64 & 2 & 67 \\
\hline Distancing & 7 & 50 & 2 & 67 \\
\hline $\begin{array}{c}\text { Positive reevaluation } \\
\text { Self control }\end{array}$ & 6 & 43 & 3 & 100 \\
\hline $\begin{array}{c}\text { Search for social } \\
\text { support }\end{array}$ & 4 & 29 & 1 & 33 \\
\hline Confrontation & 2 & 14 & - & - \\
\hline Escape-avoidance & 1 & 7 & 1 & 33 \\
\hline $\begin{array}{c}\text { Acceptance of } \\
\text { responsibility }\end{array}$ & - & - & - & - \\
\hline
\end{tabular}

Table 3: Distribution and frequency of subjects according to sex and coping strategies they use.

Source: Analysis of the results of the Lazarus Coping Styles Scale

curred in $14 \%$ of the women's group. On the other hand, both the women and men studied do not use strategies focused on accepting responsibility.

With a view to establishing the coping styles that the studied subjects possess and bearing in mind that these make mention of the existence of a type of coping preferably used by the subject (for the purposes of active or passive, controlled or uncontrolled research); The strategies or modes identified as the most frequent in the studied group were analyzed, and their correspondence with a more or less stable style or way of coping that can vary between the solution of the problem or emotional control.

In this sense, the studied group presented a great variability regarding the combination of different coping strategies, although as a whole they showed a tendency towards passive or active coping; and that in relation to their adaptive efficacy and personal control they were controlled or uncontrolled.

\begin{tabular}{|l|l|l|}
\hline \multicolumn{1}{|c|}{ Coping styles } & Number of subjects & \% \\
\hline Passives & 9 & 53 \\
\hline Controlled & 8 & 89 \\
\hline Uncontrolled & 1 & 11 \\
\hline Actives & 8 & 47 \\
\hline Controlled & 7 & 87 \\
\hline Uncontrolled & 1 & 13 \\
\hline
\end{tabular}

Table 4: Distribution and frequency of subjects according to sex and coping strategies used.

Source: Interview and results on the Lazarus Coping Styles Scale.
As can be seen in the studied group, the passive-controlled coping styles predominated slightly, represented by $89 \%$ and $87 \%$ of the cases, respectively. In another sense, only two subjects with uncontrolled coping were identified, who showed a tendency to use passive and active coping modes, in which disorganization predominated.

It is worth noting that in the case of passive coping styles, the subjects used coping strategies that highlight the presence of distancing and self-control (67\% of them); while in the active coping styles the combination of self-control and planning ( $75 \%$ of them) was presented to a greater extent among the strategies they use.

In an investigation in patients with breast cancer, problem solving, social support and wishful thinking are identified as the most frequent. And among those with the lowest scores, social withdrawal and self-criticism [8]. However, in a study carried out in cancer patients with lung cancer, the most used coping strategies in the first place were fatalism followed by the spirit of struggle; and the least used are helplessness and anxious concern [10].

On the other hand, the specialized literature recognizes the use of strategies such as social support in cancer patients has been repeatedly related to the improvement of health, and they have been part of many therapeutic interventions [11].

Zúñiga and Carazas argue that the coping patterns of the cancer patient have shown a clear relationship with the level of emotional disturbance and psychological morbidity in general, and highlight the confrontation of the problem as the most effective strategy, emphasizing the positive [1] although this strategy was not the most expressed in the group studied.

We agree with De-Haro., et al. in that the existence of one or other coping strategies is mediated by the existence of multiple factors that intervene in the way of coping, among which pathology and type of treatment granted, the patient's own characteristics (age, marital status, education, occupation, socioeconomic level) and other aspects related to the patient's environment (family type, social support, satisfactory relationship with his spouse, family functioning, satisfaction Marital [12].

The use of passive-controlled coping styles was expressed in the studied group through the use of mechanisms to control the situation or the disturbing emotions caused by the problem, mainly focused on avoiding or delaying the direct confrontation with the stimulus that causes stress, trust in the natural solution of problems to control the situation and the emotions caused by them and delegate the decision to make to other people. Furthermore, 
although less frequently, they may be able to focus on finding a solution and looking for a positive meaning to the controversial situation they face.

Taking into account the type of style that predominates and the strategies that have been identified with the greatest tendency, it could be expressed that the copes used by the patients studied are not entirely favorable and effective in the process of adaptation to the disease, because despite being Patients in the disease-free interval continuously live in an emotional state marked by anxious-depressive disorders that are closely linked with negative experiences of the disease and fear of relapse.

This prevents them from carrying out a full and satisfactory life, which allows the restructuring of the role of the patient and the use of adequate therapeutic adherence that facilitates the development of their potential and the reworking of their life projects around the existence of a better future. These aspects undoubtedly negatively influence the quality of life of the person.

On the other hand, the results obtained reflect, like other investigations carried out, the role of personality and coping mechanisms, as well as the role of stress in the quality of life of the cancer patient [2].

Table 5 illustrates the irrational beliefs that are most likely to be present in the cancer patients studied.

\begin{tabular}{|c|c|c|}
\hline Irrational beliefs & Number of subjects & $\mathbf{\%}$ \\
\hline Unique solution & 10 & 59 \\
\hline Perfection & 9 & 53 \\
\hline Competition & 8 & 47 \\
\hline External determination & 6 & 35 \\
\hline Emotional control & 4 & 24 \\
\hline Dependence & 3 & 18 \\
\hline Punishment & 2 & 12 \\
\hline Absolute approval & 2 & 12 \\
\hline Influence of the past & 2 & 12 \\
\hline Avoidance & 2 & 12 \\
\hline Fear & 1 & 6 \\
\hline
\end{tabular}

Table 5: Distribution and frequency of subjects according to irrational beliefs that appear in the studied group.

Source: Analysis of the Irrational Beliefs Questionnaire.

The most projected irrational beliefs in the studied group are the idea of a unique solution (59\% of the subjects), perfection (53\% of them), competence $(47 \%)$ and external determination (35\% of the studied subjects).
However, the results of the interview reaffirm the existence of a predominance of the belief unique solution (88\%) and perfection $(76 \%)$ and express other beliefs such as dependency (86\%), avoidance $(76 \%)$ and emotional control (65\%).

In the case of the single solution, the interviewed subjects coincide in identifying the existence of more than one solution to face the problems that affect them, although they do not deny the fact that sometimes they fantasize about the existence of an ideal solution to solve them. In this regard, many of them expressed having found solutions to their problems that, without being ideal, were effective in the face of it.

Perfection on the other hand was reflected in the interviewees' speech as a consciously elaborated personal characteristic. In this way, the subjects who expressed themselves around having this belief, show joy and pleasure when describing themselves as detailed and persistent people, aspects that are linked to obtaining the success and merit of others. Such is the case of EGG, 68, who reports: "I have always liked things well done and I have always fought against the bad done. I have been a leader and have worked for companies in other countries that have always recognized my characteristics as positive. I like things to work out as well as possible and if when I finish them I did not like the result, I will do it again until I am satisfied with it, it does not matter if I have to sacrifice myself to achieve it. Why should I be satisfied if it can be done better?".

Dependence in $86 \%$ of the subjects interviewed was presented as the need to obtain the support of the people in their family to make any decision and face a crisis or difficulty; although they point out that they are capable of making decisions by themselves. In the explanations they offer, they refer that they like to consult them with their families because in the end, in the things they face, they are always accompanied by their relatives and what affects them also affects their relatives.

Avoidance was presented in the speech of $76 \%$ of the subjects interviewed, based on expressions and behaviors that reflected it. In this sense, the existence of avoidance behaviors in the face of family problems and facing a crisis or personal difficulty were identified. An example of the latter is the presence of avoidance behaviors in the event of medical check-ups due to the possibility that during them the resurgence of the disease is identified. Such is the case of MRG, 67, who for two years has not made his follow-up consultations. She expresses: "I never thought I was going to get ahead but luckily everything was on time. The operation was quick but the recovery process was very painful. The most difficult thing came later, the chemo, I don't even want to remember. Those days were horrible and helpless. I tell my children that if I have cancer 
again, I don't want to go through all that again. Anyway, I have to die of something and if I have something bad I don't even want to find out. That is why I do not go to the Oncology to see the doctor, anyway I am fine like this".

In this case we can appreciate the negative psychological impact that the arrival of the disease has had on the person, because despite being at this time in a period free of it, he continues to update past negative experiences and fails to get rid of the negative emotions that these provoked. On the other hand, difficulties are evident in the development of adequate therapeutic adherence and in adjusting to the role of the patient; perhaps on the basis of the accumulation of negative experiences that he presented in the transit through the different stages and treatments of the disease.

Other of the irrational beliefs with higher presentation rates were emotional control and competition. In the case of the first, $65 \%$ of the interviewed subjects considered that people possess control of the emotions that disturb them; while 59\% of them reported positive expressions associated with the need to be successful, competent and intelligent in all the activities they carry out, mainly around the activities of daily life and in relation to the workplace.

In this sense, competition was associated with having an individual characteristic that favors the achievement of their goals. Such is the case of MFP, 65 years old, who refers us: "I have always liked to know a little about everything and face new challenges. When the illness came they told me that I had to retire and I had a hard time assimilating it because I have always liked being useful. When I got home and started spending time there I realized that you always have something to do. I don't have holidays, I'm always doing something, or fixing some equipment, or some key that was broken and if I don't go to my brother's house to see how I can help him. Sometimes I don't like the way things turn out or go wrong and I get mad at myself, but I repeat them until they fit. And the rest of the time I am going to receive spirituality classes because there is still a lot to learn and you must be positive in life".

As it has been possible to verify the irrational beliefs found in the studied group, they have been reflected as an important part of their story systems, which although it has been described that this type of irrational thoughts affect all people, it seems that in the studied group they vary from each other, as well as the intensity and influence they exert on the subject. We cannot ignore the fact that in the case of the cancer patient irrational thoughts hinder the acceptance of the disease, their ability to follow medical prescriptions and actively participate against the development of the disease [2].
In an investigation carried out in patients with breast cancer, it was concluded similarly to the results obtained in this investigation, that the presence of irrational ideas hindered coping with the disease and stands out as those most representative irrational ideas in the group studied emotional control, passivity and perfectionism [13]. Frustration intolerance (understood as under emotional control) produces states of stress accompanied by anxiety; helplessness (passivity) denotes an idea of resignation and an inability to do something in favor of improvement; and perfectionism is accompanied by a number of absolutisms, which, because they cannot be carried out, produce harmful side effects (stress, aggressive scenes, among others) [13].

It could be said that certain dysfunctional cognitions, automatic thoughts and irrational ideas play an important role in the initiation and maintenance of emotional disorders (anxiety, depression, anger, hostility, aggressiveness); which constitute predisposing factors to the disease, cause changes in the immune system, facilitate the role of the patient and stimulate unhealthy behaviors [9].

All this makes us think of the need to offer specialized care to cancer patients in periods free of the disease, because although the disease is in a remission phase and there is no oncospecific treatment that they are transiting; the psychological impact that this had and the psychological traces left by the medical interventions to which they were exposed continue to be present in the ways of feeling, thinking and acting of the patients studied.

For this reason, the merit of psychological therapies with cognitive approaches is recognized in the treatment of cancer patients, which underlie or influence the emotional reactions they present and which stand as responsible for the behaviors for which the patient go to treatment [11].

In the case at hand, the results reveal an emotional state with anxious-depressive disorders, which are accompanied by mainly passive-controlled coping styles and irrational beliefs marked by the search for a unique solution and perfection. For this reason, we consider the use of cognitive-behavioral psychological interventions, and especially Rational Emotional and Behavioral Therapy, to be appropriate in the subjects studied; as this type of therapy is one of the interventions that has shown the best results in the psychosocial treatment of cancer patients [12].

Therefore, the need to offer these patients specialized care that favors an increase in the quality of life and that allows the development of resources to cope with the disease continues as a working premise. Thus, providing tools for the management of those disturbing emotions and thoughts that they could experience and that negatively affect the development of the disease. 


\section{Conclusion}

An emotional state with anxious-depressive disorders was found, with a slight predominance of depression, both mainly with medium-level manifestations and reflected as a transient or reactive emotional condition to life situations.

The passive-controlled coping style predominated slightly, with a tendency to use strategies that focus mainly on self-control, distancing, planning, positive reevaluation and the search for social support.

The irrational beliefs with the highest probability of being projected in the studied group were the only solution, the search for perfection, competence and emotional control.

\section{Recommendations}

Offer systematic psychological follow-up to patients who have been diagnosed and treated for cancer.

Extension of the study to a greater number of patients with the characteristics of the subjects studied and making use of the methodology used in this study.

\section{Conflict of Interest}

There is no conflict of interest between the authors.

\section{Annexures}

Annexure 1: Informed consent

Through this document we request your collaboration and acceptance to participate in the research: Emotional states, coping styles and irrational beliefs in a group of cancer patients belonging to the Mario Escalona Teaching Polyclinic; Alamar 2016. It is a study whose general objective is to describe the emotional states, coping styles and irrational beliefs in a group of patients with this disease.

The research will allow in-depth knowledge of biopsychosocial factors in the health-disease process, with a view to promoting the development of psychological interventions that positively affect the quality of life of these patients. This research is also part of a final teaching exercise of Lic. Lien Linnet Camargo in the pass exam of the year of the Specialty in Health Psychology.

The results obtained will be confidential and will be used only for scientific purposes. Your participation will be anonymous, that is, your name will not appear in any way, either in the surveys or in the research reports that will be drawn up. In addition, you can stop participating at any time if you wish, without receiving any sanction for it.

Based on the data offered, we ask for your authorization to participate in this study
Annexure 2: Characterization of the study group

\begin{tabular}{|c|c|c|c|c|c|}
\hline $\begin{array}{c}\text { Sub- } \\
\text { jects }\end{array}$ & Age & Sex & $\begin{array}{c}\text { Schooling } \\
\text { level }\end{array}$ & Occupation & Diagnosis \\
\hline AZR & 40 & F & $\begin{array}{c}\text { Pre- } \\
\text { university }\end{array}$ & $\begin{array}{c}\text { Self- } \\
\text { employed }\end{array}$ & $\begin{array}{c}\text { Hodgkin } \\
\text { Lymphoma }\end{array}$ \\
\hline MLD & 60 & F & University & Retired & Neo thyroid \\
\hline ICR & 69 & F & Secondary & Housewife & Neo the Mama \\
\hline LDP & 69 & F & $\begin{array}{c}\text { Average } \\
\text { technician }\end{array}$ & Retired & Cervi-uterine \\
\hline GAS & 67 & F & Secondary & Housewife & Neo bladder \\
\hline CVS & 62 & M & Secondary & Retired & Neo bladder \\
\hline MJP & 58 & F & Secondary & Housewife & $\begin{array}{c}\text { Carcinoma de } \\
\text { colon }\end{array}$ \\
\hline ICR & 61 & F & University & Retired & Neo the Mama \\
\hline ECL & 67 & M & $\begin{array}{c}\text { Average } \\
\text { technician }\end{array}$ & Retired & Prostate \\
\hline Salt & 69 & F & Secondary & Housewife & Cervix-uterine \\
\hline MRG & 67 & F & $\begin{array}{c}\text { Preuniver- } \\
\text { sity }\end{array}$ & Housewife & Neo the Mama \\
\hline ALC & 66 & F & & Housewife & Neo the Mama \\
\hline IAP & 65 & M & $\begin{array}{c}\text { Average } \\
\text { technician }\end{array}$ & Retired & Prostate \\
\hline MFP & 52 & F & High school & Housewife & $\begin{array}{c}\text { Carcinoma } \\
\text { vascular }\end{array}$ \\
\hline MFP & 62 & M & University & Retired & $\begin{array}{c}\text { Colon } \\
\text { Carcinoma }\end{array}$ \\
\hline LGG & 63 & F & University & Retired & Breast Cancer \\
\hline 68 & F & High school & Housewife & $\begin{array}{c}\text { Colon } \\
\text { Carcinoma }\end{array}$ \\
\hline
\end{tabular}

\section{Bibliography}

1. Llantá Abreu MC., et al. "La Psicología de la Salud y la lucha contra el cancer" (2005).

2. Garduño C., et al. "Calidad de vida y cáncer de mama: efectos de una Intervención cognitivo-conductual". Revista Latinoamericana de Medicina Conductual 1.18 (2010).

3. Martínez Díaz IB and Roca Perara MA. "La menopausia: ¿fin de la vida útil en las mujeres? Un estudio de las creencias irracionales presentes en un grupo de mujeres menopáusicas desde la TREC [tesis]". Universidad de La Habana: Facultad de Psicología (2010).

4. Contreras F., et al. "Calidad de vida, autoeficacia, estrategias de afrontamiento y adhesión al tratamiento en pacientes con insuficiencia renal crónica sometidos a hemodiálisis" (2015).

5. MontonLlop R and EspeitxBernat E. "Propuesta de intervención para tratar la ansiedad en pacientes con cáncer de mama [Trabajo de Fin de Grado]". Universidad de Zaragoza (2012).

Participant's signature 
6. Alonso Fernández C and Bastos Flores A. "Intervención Psicológica en Personas con Cáncer. Clínica Contemporánea”. Colegio Oficial de Psicólogos de Madrid 2.2 (2011).

7. Zúñiga Rivera MS and Carazas F JC. "Efectos psicosociales de las personas que viven con cáncer en el Hospital Militar Central de la Ciudad de La Paz en el primer semestre de la gestión [tesis]". Bolivia: La Paz (2014).

8. Beatriz Páez M., et al. "Tratamiento psicológico para el afrontamiento del cáncer de mama. Estudio comparativo entre estrategias de aceptación y de control cognitive". Psicooncología 4.1 (2007): 75-95.

9. Sebastián J., et al. "Variables psicosociales y cáncer de mama: un estudio cuasiprospectivo de la personalidad tipo c". Revista Latinoamericana de Psicología 41.3 (2009).

10. Rodríguez Quintana R., et al. "Evaluación de la calidad de vida, estado emocional y estrategias de afrontamiento en pacientes con enfermedad neoplásica pulmonar". Psicooncología 9.1 (2012): 95-112.

11. Villoria E., et al. "La intervención psicológica en pacientes oncológicos: una revisión de la literatura (2000-2014)”. Psicooncología 12.2-3 (2015): 207-236.

12. De Haro Rodríguez MA., et al. "Factores relacionados con las diferentes estrategias de afrontamiento al cáncer de mama en pacientes de recién diagnóstico". Psicooncología 11.1 (2014): 87-99.

13. Escobar Espíndola SA and Moreta Herrera R. "Pacientes de género femenino con diagnóstico de cáncer de mama y su incidencia en las ideas irracionales que acuden al Hospital Dr. Julio Enrique Paredes C. de la Ciudad de Ambato [tesis]". Ecuador: Ambato (2014).

\section{Assets from publication with us}

- Prompt Acknowledgement after receiving the article

- Thorough Double blinded peer review

- Rapid Publication

- Issue of Publication Certificate

- High visibility of your Published work

Website: www.actascientific.com/

Submit Article: www.actascientific.com/submission.php

Email us: editor@actascientific.com

Contact us: +919182824667 